\title{
SCREENING OF THYMUS VULGARIS ESSENTIAL OIL AGAINST FUNGI CAUSING DERMATOPHYTOSIS IN HUMAN BEINGS
}

\author{
NEETU JAIN ${ }^{*}$, MEENAKSHI SHARMA ${ }^{2}$ \\ 1,2Laboratory of Microbiology, Department of Botany, University of Rajasthan, Jaipur \\ Email: neetugodika@yahoo.co.in
}

Received: 17 May 2017 Revised and Accepted: 31 Aug 2017

\section{ABSTRACT}

Objective: The study was designed to determined antidermatophytic activity of Thymus vulgaris essential oil against fungi causing superficial skin infections in human and animal.

Methods: Minimum inhibitory concentration (MIC) of essential oil was screened against selected pathogenic fungi namely Trichophyton rubrum (MTCC 296), T. mentagrophytes (MTCC 7687), Microsporum gypseum (MTCC 4524), M. fulvum(MTCC2837), T. soudanense and T. interdigitale through semi solid agar antifungal susceptibility testing method(SAAS). Minimum fungicidal concentration (MFC) was also determined by modified semi solid agar antifungal susceptibility method. T. soudanense and T. interdigitalis were isolated through TO. KA. VA hair bating technique from animal habitats soil of Jaipur district.

Results: T. vulgaris essential oil exhibited excellent antideramtophytic activity against all selected dermatophytes. Minimum inhibitory concentration was ranged from $0.020 \pm 0.000 \mu \mathrm{l} / \mathrm{ml}$ to $0.1 \pm 0.033 \mu \mathrm{l} / \mathrm{ml}$. MFC were found little higher than $\mathrm{MIC}(0.02 \pm 0.000 \mu \mathrm{l} / \mathrm{ml}$ to. $2 \pm 0.000 \mu \mathrm{l} / \mathrm{ml})$ M. gypseum was found to be most susceptible fungus as compared to other test fungi.

Conclusion: T. vulgaris was found to be most effective fungicidal agent against human pathogenic fungi. Present findings provide for a rationale basis of a possible utilization of this oil in fields requiring safe and cheap compounds with antiseptic and preservative properties, such as cosmetic, pharmaceutical and food industries.

Keywords: Thymus vulgaris, Essential oil, Dermatophytes, Trichophyton, Microsporum

(c) 2017 The Authors. Published by Innovare Academic Sciences Pvt Ltd. This is an open access article under the CC BY license (http://creativecommons.org/licenses/by/4.0/) DOI: http://dx.doi.org/10.22159/ijpps.2017v9i10.20054

\section{INTRODUCTION}

Infection caused by fungi in man and animal are more common in tropical and subtropical countries due to prevailing moisture, over population, poor hygienic living conditions and temperature regimes [1-5]. Skin infection due to dermatophytes has become a severe health problem affecting children, adolescent and adults. They produce keratinase which degrade the keratin and thus, invade the superficial skin tissue, nails and hair. These infections are generally cutaneous and restricted to the non-living, cornified layers of the skin. However, in constantly reoccurring conditions, the dermatophytes invade deeper tissues and simultaneously caused infections with other organisms. In general, the dermatophytes lack the ability to invade deeper tissues or organs of the host [6]. The dermatophytic infections are generally referred as ringworm infections due to their ring like appearance. Recently, there has been an increase in the incidence of fungal infections in developing countries. This may be the result of frequent use of antibiotics, environmental factors, resistant strains and various conditions, like organ transplantation, lymphomas, leukemia and human immunodeficiency virus [7]. However, clinical values of these agents have been limited due to having high toxicity and emergence of drug resistance in their antifungal activities [8]. These factors emphasize the urgent need for the development of new effective treatment alternatives.

The reduced adverse effects, decreased drug interactions, improved cure rate and cost effective medicine preparation from available topical agents are present day needs. In recent year there has been a gradual revival of interest in the use of medicinal plants and their products for the treatment dermatophytoses, and other fungal infections where a topical therapy is required. Spices and herbs are a major part of the daily food in India comprise the most important products used for flavoring foods and play a major role as the topical or systemic treatment of a wide range of diseases including infectious diseases. Beside their importance for general well-being, they are frequently used as traditional medicine [9]. In recent years, a lots of studies has been conducted on the antifungal effects of plant-derived essential oils on fungi causing superficial infections [10-14]. These finding promoted us to explore more spice essential oil for the treatment of dermatophytic infections.

Thymus vulgaris L. belonging to family Lamiaceae is a pleasan smelling perennial shrub, cultivating all over the world. Thyme is widely used for seasoning fish, poultry farms, vegetables, soups, for flavoring liqueurs, herbal tea preparations. T. vulgaris essential oil and extract has also been used in the treatment of gum diseases, rheumatism, sore throat, tonsillitis, and arthritis [15-16]. The essential oil of T. vulgaris is a known antiseptic, antiviral, antimicrobial agents [17-20]. Lots of work on antifungal activity of T. vulgaris essential oil against plant pathogenic, food born fungi, saprophytic fungi and Candida albicans has been reported [21-24] but very few reports are available on the management of human pathogenic fungi using Thymus oil despite its proven biological actions.

In present investigation a most important spice of European countries, T. vulgaris L. was explore against dermatophytic fungi. The high antidermatophytic activity suggests that thymus essential oil is a potential new antifungal agent for a natural product.

\section{MATERIALS AND METHODS}

Plant essential oil

Essential oil of Thymus vulgaris (red thyme) was procured from sigma Aldrich (São Paulo, SP, Brazil) company. Oil was clear light yellow colour with pleasant odor. Oil was stored in refrigerator.

\section{Chemical and reagents}

Sabouraud dextrose agar and Brain heart infusion agar media were purchased from Sigma Aldrich chemical company.

\section{Microorganism for in vitro studies}

T. vulgaris essential oil was evaluated for their antifungal properties against selected dermatophytes and keratinophilic fungi. For 
antidermatophytic studies four dermatophytes were procured from the Imtech Chandigarh. These are T. mentagrophytes (MTCC 7687), M. gypseum (MTCC 4524) and Microsporum fulvum (MTCC2837), T. rubrum (MTCC 296). Trichophyton soudanense and T. interdigitale were isolated from soil sample collected from animal habitats of Jaipur district. These fungi were isolated through TO. KA. VA hair baiting technique of Vanbreuseghem [25]. Identification was based on macroscopic and microscopic examination of the culture isolates. The macroscopic examination of fungi was characterized by duration of growth, surface morphology and pigment production on the reverse. Strains were identified by their morphological and physiological characteristics according to the procedure described by Conant $e$ t al.,[26] and Forbes et al., [27]. These selected fungi are maintained on Sabouraud's dextrose agar media and Potato dextrose agar media. Cultures were stored at $4{ }^{\circ} \mathrm{C}$ and sub cultured once in the month.

\section{Determination of MIC and MFC by semisolid agar antifungal susceptibility method (SAAS)}

Semisolid agar antifungal susceptibility testing method of Provine and Hadley [28] was applied for end point determination. For this method Brain heart agar medium was used.

\section{Inoculum preparation}

Sterile swab dipped into sterile tween 80 was used to pick the pure colony of yeast. This was then suspended in 3-4 ml of sterile normal saline and vortexed. The turbidity of the homogenous suspension was adjusted to $\sim 0.5$ McFarland standard. Similarly inoculum was prepared for filamentous fungi $\left(3-7 \mathrm{~d}\right.$ old slant at $37{ }^{\circ} \mathrm{C}$ on potato dextrose agar). By swabbing the pure colony (mixture of conidia and hyphal fragments) was suspended in 3-7 $\mathrm{ml}$ of sterile saline. The mixture was vortexed and heavy particles were allowed to settle. The homogenous suspension was adjusted to $0.5 \mathrm{McF}$ arland standard.

\section{Inoculation of drug containing tubes}

The semisolid agar tubes containing known concentrations of test oils as well as oil-free controls, prepared in duplicate, were inoculated with one loopful (Himedia Flexiloop 4) of 0.5 McFarland adjusted culture by inserting the loop deep within the semisolid agar. The tubes were incubated at $37^{\circ} \mathrm{C}$ for $72 \mathrm{~h}$ for dermatophytes. A loopful of the inoculum suspension was streaked onto Sabouraud dextrose agar to check for purity and viability.

\section{End point determination}

Endpoint determination was done according to the NCCLS/CLSI guidelines, M27-A and M38-A. Growth was compared to that of oilfree control and scored by visual inspection as follows: +4 : growth same as control; +3 : slight decrease in growth; +2 : significant reduction in growth reduction $80 \%$ in yeast and $50 \%$ in filamentous);+1 slight growth or few visible hyphal fragments; 0 : no growth.

MFC was recorded through slightly modification of SAAS method. After 72 hour observation of drug containing tubes for MIC, these tubes were further restored as same temperature conditions for 3-4 more days. Observation were recorded for MFC.

\section{Statistical analysis}

Each parameter was tested in triplicate. Conventional statistical methods were used to calculated means and standard deviations. Statistical analysis (T-test) was applied to the data to determine differences $(\mathrm{p}<0.05)$

\section{RESULTS}

T. vulgaris an important spice is widely used in various ailments. Lots of work has been done on the chemical composition of Thyme oil [20,22,29-30]. Thymol is major constituents of oil ranging from $42.6-57.8 \%$ according to collection time and cultivation place. Other components are $\alpha$-cymene, carvacrol, $\alpha$-thujene, $\alpha$-pinene, $\beta$ myrcene, trans-ocimene, $\gamma$ terpinene, limonene.

Preliminary screening of the $T$. vulgaris essential oil for antidermatophytic activity was carried out against six selected dermatophytic fungi using semi solid agar antifungal susceptibility method. Data incorporated in table 1 show MIC and MFC of Thyme essential oil.

Thyme oil exhibited excellent antifungal potential against all selected fungi. Microsproum gypseum was found most susceptible fungus $(0.020 \pm 0.000 \mu \mathrm{l} / \mathrm{ml})$ followed by $T$. mentagrophytes $(0.05 \pm 0.000 \mu \mathrm{l} / \mathrm{ml}), T$. interdigitale $(0.05 \pm 0.000 \mu \mathrm{l} / \mathrm{ml})$ and $T$. soudanense $(0.053 \pm 0.003 \mu \mathrm{l} / \mathrm{ml})$. M. fulvum $(0.1 \pm 0.033 \mu \mathrm{l} / \mathrm{ml})$ was less susceptible fungus as compared to other test fungi. MFC was same to MIC in case of $M$. gypseum $(0.020 \pm 0.000 \mu \mathrm{l} / \mathrm{ml})$ and $T$. mentagrophytes $(0.05 \pm 0.003 \mu \mathrm{l} / \mathrm{ml})$. MFC against M. fulvum was found to be $0.2 \pm 0.000 \mu \mathrm{l} / \mathrm{ml}$.

Table 1: Antifungal activity of Thymus vulgaris essential oil against dermatophytic fungi

\begin{tabular}{lll}
\hline Activity fungi & MIC $(\boldsymbol{\mu l} / \mathbf{m l})$ \\
\hline Trichophyton mentagrophytes MTCC 7687 & $0.05 \pm 0.000$ \\
Microsporum fulvum MTCC2837 & $0.10 \pm 0.033$ \\
Trichophyton rubrum MTCC 296 & $0.026 \pm 0.002$ \\
Microsporum gypseum MTCC 4524 & $0.020 \pm 0.000$ \\
Trichophyton interdigitale & $0.05 \pm 0.000$ \\
Trichophyton soudanense & $0.053 \pm 0.003$ \\
\hline
\end{tabular}

MIC=minimum inhibitory concentration, $\mathrm{MFC}=$ minimum fungicidal concentration, Statistical analysis was carried out through $\mathrm{T}$-test $(\mathrm{p}<0.05)$.

\section{DISCUSSION}

T. vulgaris L. (Lamiaceae) is a well-known medicinal shrub that contains important phenolic compounds such as thymol and carvacrol and it has been used in many pharmaceutical applications. Data incorporated in present studies revealed strong antidermatophytic activity of $T$. vulgaris essential oil against all selected filamentous fungi namely T. mentagrophytes, T. rubrum, T. interdigitale, T. soudanense, M. fulvum and M. gypseum. MIC was ranged between $0.020 \pm 0.000$ to $0.1 \pm 0.033 \mu \mathrm{l} / \mathrm{ml}$. These promising antifungal activity against all selected pathogenic fungi may be due to presence of high concentration of phenolic compounds. Similar results were also contributed by other researchers. Shigeharu Inouye et al. [31] studied the vapour activity of 72 essential oil on $T$. mentagrophytes. Oils containing phenol as the major constituent showed the most prominent vapor activity, with an MFD of 1.56 $\mu \mathrm{g} / \mathrm{ml}$ air. They suggested that essential oils such thyme thymol, wild thyme exhibited potent vapor activity against $T$. mentagrophytes may be useful as room disinfectants when patients with tinea pedis may drop the living pathogens on the floor.

Soković et al.[29] studied the chemical composition of T. vulgaris essential oil and their antifungal activity against 17 micromycetal food poisoning, plant, animal and human pathogens. MIC and MLC were tested against five dermatophytic fungi namely Microsporum canis, Epidermophyton floccosum, Trichophyton rubrum, T. mentagrophytes and $T$. tonsurans. The essential oil of $T$. vulgaris showed very strong antifungal activity at low concentrations, 0.05$1.0 \mu \mathrm{l} / \mathrm{ml}$. Pina-Vaz et al. [32] screened Thymus vulgaris, T. zygis sub species zygis and T. mastichina sub species mastichina essential oils and their major components (carvacrol, thymol, $p$-cymene and 1,8cineole) against different strain and species of Candida. The essential 
oils of T. vulgaris and T. zygis showed similar antifungal activity, which was greater than T. mastichina. MIC and MLC values were similar for all the compounds tested.

During present investigation, M. gypseum was found to be most susceptible fungus, where MIC and MFC were found similar. MIC of $T$. vulgaris against T. rubrum was also $0.026 \pm 0.002 \mu \mathrm{l} / \mathrm{ml}$ but MFC was slightly increased $(0.05 \pm 0.003 \mu \mathrm{l} / \mathrm{ml})$. MFC of essential oil was slightly increased as compared to MIC against all filamentous fungi. MFC were ranged from $0.020 \pm 0.00 \mu \mathrm{l} / \mathrm{ml}$ to $0.2 \pm 0.000 \mu \mathrm{l} / \mathrm{ml}$. Adams et al.[33] described that the high antifungal activity of Thyme essential oil are due to presence of the high percentage of phenol components. It believed that phenol components may interfere with cell wall enzymes like chitin synthase/chitinase as well as with the $\alpha$-and $\beta$-glucanases of the fungus. Consequently, the high content of phenol components may account for the high antifungal activity of oils [34]. Rota et al. [20] explained that presence of phenolic compounds thymol and carvacrol are responsible factors of excellent antifungal activities of $T$. vulgaris oil. The antifungal activity of the oil is mostly incorporated with the interaction of phenolic compounds, thymol, carvacrol, and p-cymene with cytoplasmic membrane ergostrol [22, 32]. It is believed that the hydroxyl group on these compounds interact on the cytoplasmic membrane and changes its permeability by affecting lipid ordering and stability of its bilayer. Therefore proton passive flux across the membrane increased, which disrupted the cytoplasmic membrane and leading to leakage of cellular contents [35-38]. Antifungal activity of the essential oil of T. vulgaris $\mathrm{L}$. and Thymol on experimentally induced dermatomycoses was carried out by Sokovi et al. [29] and found excellent results.

\section{CONCLUSION}

This study is a preliminary evaluation of antimicrobial activity of the Thymus plant essential oil.

Present study concluded that the essential oil of $T$. vulgaris is highly active as fungitoxicants and could safely be used as natural preservatives to replace synthetic allopathic preparations in the prevention and cure of superficial skin infection. The plant presented broad spectra of activity, may help to discover new antibiotics that could serve as selective agents for the maintenance of animal or human health and provide biochemical tools for the study of infectious diseases. This versatile medicinal plant is the unique source of various types of chemical compounds, which are responsible for the various activities of the plant. Hence the extensive investigation is needed to exploit their therapeutic utility to combat diseases.

\section{ACKNOWLEDGEMENT}

Authors are thankful to University Grant Commission, New Delhi, India for providing financial assistance during research work (Award letter no 15-34/12(SA-II)dated 23.1.2012). The authors are also thankful to Head of the Botany Department, University of Rajasthan, Jaipur for providing laboratory facilities.

\section{AUTHOR'S CONTRIBUTION}

Neetu Jain researched and wrote the article while Meenakshi Sharma provided guidance, critical review, and revision. All authors read and approved the final version of present manuscript.

\section{CONFLICT OF INTERESTS}

No conflict of interest

\section{REFERENCES}

1. Weitzman I, Summerbell R. The dermatophytes. Clin Microbiol 1995;8:240-59.

2. Maraki S, Tselentis Y. Dermatophytoses in crete, greece between 1992 and 1996. Mycoses 1998;41:175-8.

3. Ameen M. Epidemiology of superficial fungal infections. Clin Dermatol 2010;28:197-201.

4. Newze EI. Dermatophytoses in Western Africa: a reivew. Pak J Biol Sci 2010;13:649-56.

5. Jain N, Sharma M, Sharma M, Saxena VN. Spectrum of dermatophytoses in Jaipur, India. Afr J Microbiol Res 2014;8:237-43.
6. Bhatia VK, Sharma CP. Epidemiological studies on dermatophytosis in human patients in Himachal Pradesh, India. Springler Plus 2014;3:134.

7. Petmy LJ, Lando AJ, Kaptue L, Tchinda V, Folefack M. Superficial mycoses and HIV infection in Yaounda. J Eur Acad Dermatol Venerol 2004;8:301-4.

8. Watanabe S. Present state and future direction of topical antifungals. Japaneses J Med Mycol 1990;40:151-5.

9. Mandeel QA, Al-Laith AA. Ethnomycological aspects of the desert truffle among native Bahraini and non-Bahraini peoples of the Kingdom of Bahrain. J Ethnopharmacol 2007;110:11829.

10. Jain N, Sharma M. Broad spectrum antimycotic drug for the treatment of ring worm infection in human beings. Curr Sci 2003;85:30-4.

11. Shahi SK, Shahi MP, Choudhary S, Kumar M. Broad spectrum herbal antifungal compound for the cure of human dermatophytoses. Plant Arch 2007;7:771-3.

12. Kalita L, Dash B, Borah U, Deka J, Dash S. Preliminary phytochemical analysis and antimicrobial activity ethanolic extracts of dried fruits of Solanum torvum (family-Solanaceae). Int J Curr Pharm Res 2017;9:123-6.

13. Jalila El Amri, Khalid El Badaoui, Zoubida Halouia. The chemical composition and the antimicrobial properties of the essential oil extracted from the leaves of Teucrium capitatum L. Asian J Pharm Clin Res 2017;10:112-5.

14. Jain N, Sharma M. Screening of Lawsonia inermis essential oil against fungi causing dermatophytic infection in human. Asian J Pharm Clin Res 2016;9:67-9.

15. Van Vuuren SF, Suliman S, Viljoen AM. The antimicrobial activity of four commercial essential oils in combination with conventional antimicrobials. Lett Appl Microbiol 2009;48:440-6.

16. Ali Ahmad Al Maqtari M, Alghalibi SM, Alhamzy EH. Chemical composition and antimicrobial activity of essential oil of Thymus vulgaris from Yemen. Turk J Biochem 2011;36:342-9.

17. Hammer KA, Carson CF, Riley TV. Antimicrobial activity of essential oils and other plant extracts. J Appl Microbiol 1999;86:985-90.

18. Duke OS, Dayan EF, Romagani JG, Rimando MA. Natural products as sources of herbicides current status and future trends. Weed Res 2000;40:99-111.

19. Bremnes L. Herbs. Eyewitness-Handbooks; DK Publishing: New York, USA; 2002.

20. Rota MC, Herrera A, Martínez RM, Sotomayor JA, Jordán MJ. Antimicrobial activity and chemical composition of Thymus vulgaris, Thymus zygis and Thymus hyemalis essential oils. Food Control 2008;19:681-7.

21. Sacchetti G, Maietti S, Muzzoli M, Scaglianti M, Manfredini S, Radice M, et al. Comparative evaluation of 11 essential oils of different origin as functional antioxidants, antiradicals and antimicrobials in foods. Food Chem 2005;91:621-32.

22. Lira Mota KS, Oliveira Pereia F, Oliveira WA. Antifungal activity of Thymus vulgaris L. essential oil and its constituent phytochemicals against Rhizopus oryzae: interaction with ergosterol. Molecules 2012;17:14418-33.

23. Rus C, Sumalan RM, Alexa E, Copolovici DM, Pop G, Botau D. Study on chemical composition and antifungal a ctivityof essential oils obtained from representative species belonging to the Lamiaceae family. Plant Soil Environ 2015;61:297-302.

24. Fani MM, Jamshid Kohanteb. In vitro antimicrobial activity of Thymus vulgaris essential oil against major oral pathogens. J Evidence-Based Complementary Altern Med 2017;1-7. Doi:10.1177/2156587217700772

25. Vanbreuseghem R. Technique biologique pour l'isolment des dermatophytes du sol (Biological technique for the isolation of dermatophytes from the soil). Ann Soc Belge Med Trop 1952;32:173-8

26. Conant Norman F, Smith David T, Baker Roger D, Callaway Jasper L, Martin Donald S. Mycology of dermatomycoses. In: Manual of Clinical Mycology, Philadelphia: W. A. Saunders company; 1959. p. 329-52.

27. Forbes Betty A, Sahm Daniel F, Weissfeld Alice S. Laboratory methods in basic mycology. Bailey and Scott's Diagnostic Microbiology (Eleventh edition). Mosby, Inc; 2002. p. 711-97. 
28. Provine H, Hadley S. Preliminary evaluation of a semisolid agar antifungal susceptibility test for yeast and molds. J Clin Microbiol 2002;38:537-41.

29. Soković MD, Jelena Vukojević, Petar D Marin, Dejan D Brkić, Vlatka Vajs, Leo J L D van Griensven. Chemical composition of essential oils of Thymus and Mentha species and their antifungal activities. Molecules 2009;14:238-49.

30. Boruga O, Jianu C, Misca C, Goleţ I, Gruia AT, Horhat FG. Thymus vulgaris essential oil: chemical composition and antimicrobial activity. J Med Life 2014;7:56-60.

31. Shigeharu Inouye, Katsuhisa Uchida, Shigeru Abe. Vapor activity of 72 essential oils against a Trichophyton mentagrophytes. J Infect Chemother 2006;12:210-6.

32. Pina-Vaz C, Goncalves Rodrigues A, Pinto E, S Costa-de-Oliveira, C Tavares, L Salgueiro, et al. Antifungal activity of Thymus oil and their major compounds. J Eur Acad Dermatol Venereol 2004;18:73-8

33. Adams S, Kunz B, Weidenbörner M. Mycelial deformations of Cladosporium herbarum due to the application of Eugenol and Carvacrol. J Essent Oil Res 1996;8:535-40.
34. Adams K, Sivropoulou A, Kokkini S, Lanaras T, Arsenakis M. Antifungal activities of Origanum vulgare subsp. hirtum, Mentha spicata, Lavandula angustifolia and Salvia fruticosa essential oils against human pathogenic fungi. J Agric Food Chem 1998;46:1738-45

35. Shapiro S, Guggenheim B. The action of thymol on oral bacteria. Oral Microbiol Immunol 1995;10:241-6.

36. Dorman HJD, Deans SG. Antimicrobial agents from plants: antimicrobial activity of plant volatile oils. J Appl Microbio 2000;88:308-16.

37. $\mathrm{Xu}$ J, Zhou F, Ji BP. The antibacterial mechanism of carvacrol and thymol against Escherichia coli. Lett Appl Microbiol 2008;47:174-9.

38. Ahmad A, Vuuren SV, Viljoen A. Unraveling the complex antimicrobial interactions of essential oils-the case of Thymus vulgaris (thyme). Molecules 2014;19:2896-910.

\section{How to cite this article}

- $\quad$ Neetu Jain, Meenakshi Sharma. Screening of Thymus vulgaris essential oil against fungi causing dermatophytosis in human beings. Int J Pharm Pharm Sci 2017;9(10):236-239. 